\title{
BMJ Open Does diabetes influence the probability of experiencing chronic low back pain? A population-based cohort study: the Nord-Trøndelag Health Study
}

\author{
Ingrid Heuch, ${ }^{\oplus 1}$ Ivar Heuch, ${ }^{2}$ Knut Hagen, ${ }^{3,4}$ Elin Pettersen Sørgjerd, ${ }^{5}$ \\ Bjørn Olav Åsvold, ${ }^{5,6}$ John-Anker Zwart ${ }^{1,7}$
}

To cite: Heuch I, Heuch I, Hagen $\mathrm{K}$, et al. Does diabetes influence the probability of experiencing chronic low back pain? A population-based cohort study: the Nord-Trøndelag Health Study. BMJ Open 2019;9:e031692. doi:10.1136/ bmjopen-2019-031692

\section{- Prepublication history for} this paper is available online. To view these files, please visit the journal online (http://dx.doi org/10.1136/bmjopen-2019031692)

Received 15 May 2019 Revised 10 August 2019 Accepted 19 August 2019
Check for updates

(C) Author(s) (or their employer(s)) 2019. Re-use permitted under CC BY-NC. No commercial re-use. See rights and permissions. Published by BMJ.

For numbered affiliations see end of article.

Correspondence to Dr Ingrid Heuch; ingrid.heuch@ous-hf.no

\section{ABSTRACT}

Objective Low back pain (LBP) is a major problem in modern society and it is important to study possible risk factors for this disorder. People with diabetes are often affected by LBP, but whether diabetes represents a risk factor for LBP has not been studied in detail. The aim of this study was to explore the association between diabetes and subsequent risk of chronic LBP.

Design An 11-year follow-up study.

Setting The Nord-Trøndelag Health Study (HUNT2; 19951997) and HUNT3 (2006-2008) surveys of Nord-Trøndelag County in Norway.

Main outcome measure Chronic LBP, defined as LBP persisting at least 3 months continuously during the last year.

Participants A total of 18972 persons without chronic LBP at baseline in HUNT2, and 6802 persons who reported chronic LBP at baseline in HUNT2.

Methods Associations between diabetes and risk of chronic LBP among individuals aged 30-69 years were examined by generalised linear modelling.

Results Men without chronic LBP at baseline showed a significant association between diabetes and risk of chronic LBP (relative risk (RR) 1.43, 95\% Cl 1.04 to 1.96, $p=0.043)$. In women, no association was found (RR $1.01,95 \% \mathrm{Cl} 0.69$ to $1.48, \mathrm{p}=0.98$ ). No association could be established between diabetes and recurrence or persistence of chronic LBP after 11 years in either sex. Conclusions Men with a diagnosis of diabetes may have a higher risk of subsequently experiencing chronic LBP.

\section{INTRODUCTION}

Low back pain (LBP) constitutes a significant health problem in today's society ${ }^{1}$ and it is important to explore possible risk factors associated with the disorder. Diabetes is increasing in prevalence worldwide, with possible serious implications. ${ }^{2}$ An association between diabetes and LBP has been indicated in some population studies. ${ }^{34}$ Other studies have suggested a relationship between increased blood glucose levels and LBP. ${ }^{56}$ It has also been suggested that lumbar spinal

\section{Strengths and limitations of this study}

The study is prospective with a long follow-up period of 11 years.

- The target population represents an entire Norwegian county in the relevant age range.

- The information about low back pain is self-reported in a questionnaire.

No information about pain intensity was available.

stenosis may be associated with diabetes mellitus. ${ }^{7}$

Animal models have supported the existence of an association between type 2 diabetes and structural spinal changes ${ }^{8}$ and between a prediabetic state and spinal degenerative changes in the vertebral structure. ${ }^{9}$ Moreover, LBP and diabetes have important risk factors in common, as overweight and obesity, ${ }^{10} 11$ physical inactivity ${ }^{12} 13$ and smoking. ${ }^{14} 15$

Few epidemiological studies have looked at relations between diabetes and back pain. ${ }^{16}$ In a recently published study, women who experienced chronic LBP were found to have an increased risk of being diagnosed with diabetes in the subsequent 11-year interval. ${ }^{17}$ Very few studies have considered diabetes as a risk factor for LBP. An association between prevalence of chronic LBP and diabetes was observed in a large cross-sectional study. ${ }^{18}$ In a 4-year longitudinal study, a higher risk of back, neck and/or shoulder pain was found among individuals with diabetes. ${ }^{19}$ A study of twins found that back pain was associated with the prevalence of diabetes, but diabetes did not significantly increase the risk of back pain in a follow-up of 2-4 years. ${ }^{3}$ Among patients having a diagnosis of either type 1 or type 2 diabetes, markers of increased diabetes disease burden were associated with the presence of back pain. ${ }^{20}$ 
The objective of the current study was to explore relationships between diabetes and risk of chronic LBP in a Norwegian population, adjusting for established risk factors. The following questions are addressed. Among individuals without chronic LBP, does the risk of chronic LBP experienced after 11 years depend on having diabetes at start of follow-up? Among those with chronic LBP at start of follow-up, does diabetes increase the probability of recurrence or persistence of chronic LBP at the end of the 11-year follow-up period? The same data set has previously been used to study risk of chronic LBP depending on body mass index (BMI), ${ }^{10}$ several measures of body size $^{21}$ and physical activity level in leisure time. ${ }^{12}$

\section{METHODS}

\section{Basic information}

Three consecutive health surveys have been conducted in Nord-Trøndelag County in Norway ${ }^{22}$ : the Nord-Trøndelag Health Study (HUNT1) in 1984-1986, HUNT2 in 19951997 and HUNT3 in 2006-2008. This work combines baseline data from the second survey, HUNT2, ${ }^{23}$ with follow-up data from the third survey, HUNT3 ${ }^{22}$ All residents of the county aged 20 years and above were invited to take part in the HUNT2 survey. They were requested to complete a questionnaire on health status, and they were invited to a clinical consultation, including measurement of height and weight. In the HUNT3 survey 11 years later, similar information was collected using a questionnaire and a clinical examination. Each participant in the HUNT2 and HUNT3 surveys signed a written informed consent regarding the collection and use of data for research purposes.

One question in the HUNT2 and HUNT3 questionnaires was expressed in this way: 'During the last year, have you suffered from pain and/or stiffness in your muscles and joints that has lasted for at least 3 consecutive months?' Each participant answering yes was given the following question: 'Where did you have these complaints?' Several body regions were listed. Individuals answering yes to the first question and including the lower back as a relevant region were regarded as having chronic LBP. ${ }^{24}$

Another question in the HUNT2 questionnaire was: 'Do you have or have you had diabetes?' The self-report had excellent positive (96.4\%) and negative (99.7\%) predictive values in a validation study comparing self-reported diabetes in HUNT1 with records of general practitioners. ${ }^{25}$ The participants in HUNT2 also gave information regarding physical activity in leisure time and smoking, and information needed for determining Hospital Anxiety and Depression Scale (HADS) scores. ${ }^{26}$

\section{Study design}

Because of lower participation rate in relatively large parts of the youngest and oldest age groups invited, ${ }^{27}$ this study was restricted to respondents aged 30-69 years when they participated in HUNT2. Information about

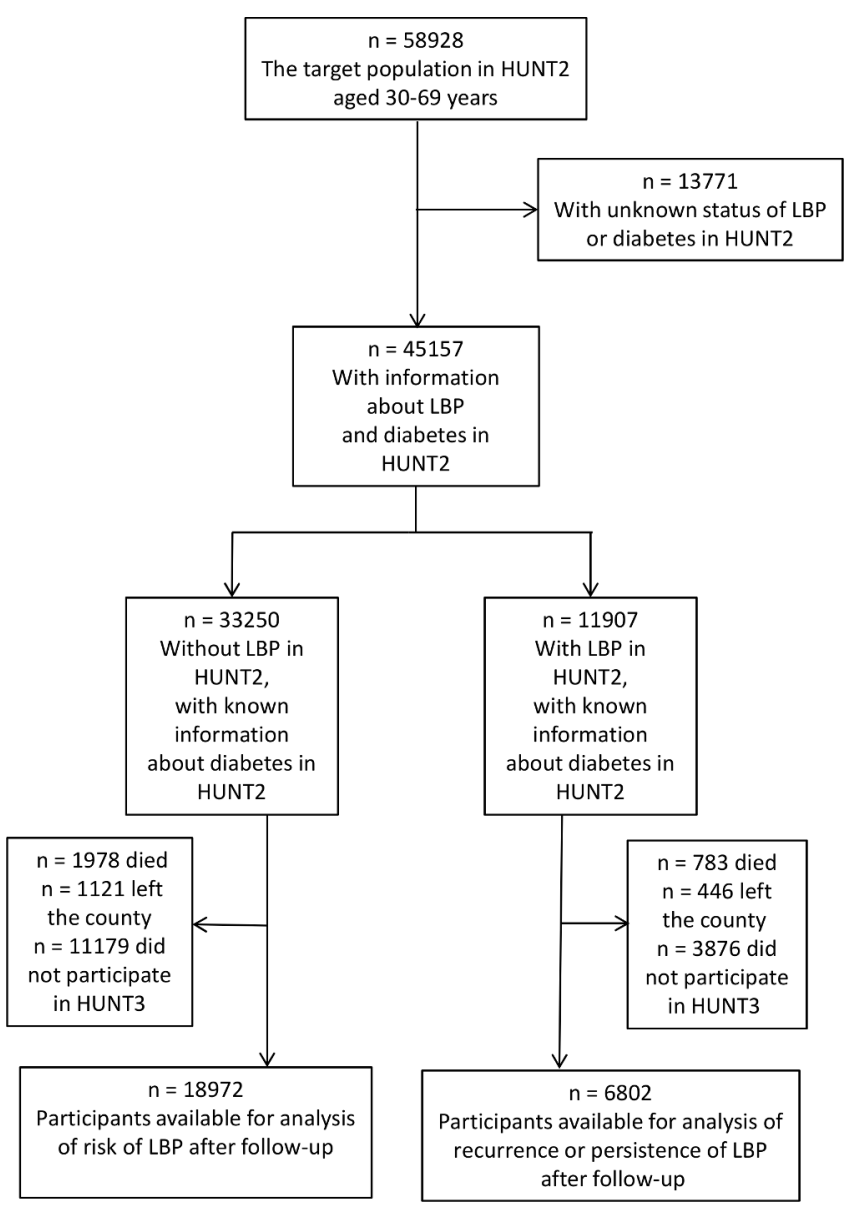

Figure 1 Flow chart for the study. HUNT, Nord-Trøndelag Health Study; LBP, low back pain.

residence status was obtained from national registries and linked using the unique Norwegian personal identification numbers. At the time of the HUNT2 survey, the total population consisted of 58928 persons in the age interval of 30-69 years (figure 1). An 11-year prospective study was carried out using baseline data from HUNT2 in combination with follow-up data from HUNT3. The study aimed at the cohort consisting of 45157 individuals with information about presence or absence of chronic LBP and diabetes in HUNT2. This cohort included 33250 individuals without chronic LBP in HUNT2 and 11907 individuals with chronic LBP in HUNT2.

During the period of follow-up, 2761 members of this cohort died and 1567 individuals left the county of Nord-Trøndelag (figure 1). Furthermore, 15055 members of the cohort residing in Nord-Trøndelag at the time of HUNT3 did not participate or did not supply information about chronic LBP. Thus, a total of 25774 individuals could be considered in the prospective study, including 18972 individuals in the analysis of risk among those initially free of chronic LBP, and 6802 individuals in the analysis of recurrence or persistence of chronic LBP among those with chronic LBP at baseline. The total number represented $63.1 \%$ of the remaining individuals resident in the county and $57.1 \%$ of the original cohort. 
Table 1 Number of individuals included in the study of risk of LBP, among individuals without chronic LBP at baseline

\begin{tabular}{|c|c|c|c|c|}
\hline & \multicolumn{2}{|l|}{ Women } & \multicolumn{2}{|l|}{ Men } \\
\hline & Total $\mathbf{n}$ & $\begin{array}{l}\text { With chronic } \\
\text { LBP in } \\
\text { HUNT3 } \\
\mathrm{n}(\%)\end{array}$ & Total n & $\begin{array}{l}\text { With chronic } \\
\text { LBP in } \\
\text { HUNT3 } \\
\text { n (\%) }\end{array}$ \\
\hline \multicolumn{5}{|c|}{ Age at baseline (year) } \\
\hline 30-39 & 2819 & $552(19.6)$ & 2106 & 305 (14.5) \\
\hline $40-49$ & 3317 & $710(21.4)$ & 2883 & $464(16.1)$ \\
\hline $50-59$ & 2513 & 495 (19.7) & 2366 & $316(13.4)$ \\
\hline $60-69$ & 1601 & $348(21.7)$ & 1367 & $190(13.9)$ \\
\hline \multicolumn{5}{|c|}{ BMI at baseline $\left(\mathrm{kg} / \mathrm{m}^{2}\right)$} \\
\hline$\leq 24.9$ & 4820 & 911 (18.9) & 2837 & $355(12.5)$ \\
\hline $25-29.9$ & 3892 & $846(21.7)$ & 4715 & 708 (15.0) \\
\hline $30-34.9$ & 1178 & 258 (21.9) & 1019 & $188(18.4)$ \\
\hline$\geq 35$ & 334 & $85(25.4)$ & 128 & $21(16.4)$ \\
\hline \multicolumn{5}{|l|}{ Diabetes } \\
\hline Absent & 10134 & $2082(20.5)$ & 8562 & $1244(14.5)$ \\
\hline Present & 116 & $23(19.8)$ & 160 & $31(19.4)$ \\
\hline
\end{tabular}

BMI, body mass index; HUNT, Nord-Trøndelag Health Study; LBP, low back pain.

\section{Covariates}

Baseline age was represented by 10-year intervals in the main statistical analyses. BMI, defined as weight $/$ height $^{2}$, in $\mathrm{kg} / \mathrm{m}^{2}$, was subdivided into four groups with limits consistent with the standard WHO definitions (except for categories at the extreme ends): $\leq 24.9,25-29.9,30-34.9$ and $\geq 35$. For physical activity in leisure time, including going to work, one category represented light activity only or hard physical activity (leading to sweating or being out of breath) less than 1 hour/week. Other categories represented hard physical activity 1-2 hours/week, and 3 or more hours/week. The information collected on hard activity in leisure time showed acceptable repeatability in a reliability and validity study, and seemed to be a reasonably valid measure of vigorous activities. ${ }^{28}$ Categories of cigarette smoking represented current daily smoking, previous daily smoking and never daily smoking.

\section{Statistical analyses}

Associations between diabetes and risk of chronic LBP were assessed by generalised linear modelling for binomial observations with a $\log$ link, with adjustment for potential confounders. In view of sex contrasts in overall risk and in associations of other risk factors with diabetes $^{29}$ and $\mathrm{LBP}^{30}{ }^{30}$ all analyses were performed separately for women and men. In the main analyses, all variables adjusted for were regarded as categorical. Initial analyses involved adjustment for age only, and adjustment was then added for other factors known to affect both the risk of LBP and diabetes, as BMI, ${ }^{11} 1631$ physical activity in leisure time ${ }^{1213}$ and smoking. ${ }^{1415}$ Separate tests
Table 2 Associations between diabetes at baseline and risk of chronic LBP in HUNT3, among individuals without chronic LBP at baseline

\begin{tabular}{|c|c|c|}
\hline & Women & Men \\
\hline \multicolumn{3}{|c|}{ Adjustment for age } \\
\hline $\mathrm{RR}(95 \% \mathrm{Cl})$ & 0.95 (0.66 to 1.37$)$ & 1.38 (1.00 to 1.90$)$ \\
\hline$P$ value & 0.78 & 0.07 \\
\hline $\begin{array}{l}\text { Number of } \\
\text { individuals } \\
\text { included }\end{array}$ & 10250 & 8722 \\
\hline \multicolumn{3}{|c|}{ Adjustment for age and BMI } \\
\hline $\mathrm{RR}(95 \% \mathrm{Cl})$ & 0.92 (0.63 to 1.32$)$ & $1.34(0.97$ to 1.84$)$ \\
\hline$P$ value & 0.63 & 0.097 \\
\hline $\begin{array}{l}\text { Number of } \\
\text { individuals } \\
\text { included }\end{array}$ & 10224 & 8699 \\
\hline \multicolumn{3}{|c|}{ Complete adjustment* } \\
\hline $\mathrm{RR}(95 \% \mathrm{Cl})$ & $1.01(0.69$ to 1.48$)$ & $1.43(1.04$ to 1.96$)$ \\
\hline$P$ value & 0.98 & 0.043 \\
\hline $\begin{array}{l}\text { Number of } \\
\text { individuals } \\
\text { included }\end{array}$ & 9590 & 8331 \\
\hline
\end{tabular}

*Adjustment for baseline age, BMI, physical activity and smoking.

BMI, body mass index; HUNT, Nord-Trøndelag Health Study; LBP, low back pain; $R R$, relative risk.

were carried out for interaction between diabetes and each factor adjusted for. Age and BMI were considered as continuous variables with a potential effect represented by a cubic polynomial in separate sensitivity analyses with more detailed adjustment.

Because information on potential confounders was missing in a minor part of the data set, analyses with complete adjustment included a slightly lower number of individuals than the age-adjusted analyses. The total number of individuals considered in each analysis is indicated in the tables. The overall HADS scores were available only for $87 \%$ of the individuals included in the analyses, and few individuals had high scores. For this reason, additional adjustment for HADS score was only performed in separate sensitivity analyses, with the score regarded as a continuous variable.

All statistical analyses were carried out using IBM SPSS V.25 (IBM).

\section{Patient and public involvement}

There was no patient or public involvement in the design or implementation of this study.

\section{RESULTS}

In the cohort study of individuals without LBP at baseline, a total of 2105 women (20.5\%) and 1275 men (14.6\%) reported chronic LBP at end of follow-up. The crude incidence of LBP depended substantially on BMI but not 
Table 3 Number of individuals included in the study of recurrence/persistence of chronic LBP, among individuals with chronic LBP at baseline

\begin{tabular}{|c|c|c|c|c|}
\hline & \multicolumn{2}{|l|}{ Women } & \multicolumn{2}{|l|}{ Men } \\
\hline & Total $\mathbf{n}$ & $\begin{array}{l}\text { With chronic } \\
\text { LBP in HUNT3 } \\
\text { n (\%) }\end{array}$ & Total $\mathbf{n}$ & $\begin{array}{l}\text { With chronic } \\
\text { LBP in HUNT3 } \\
\mathrm{n}(\%)\end{array}$ \\
\hline \multicolumn{5}{|c|}{ Age at baseline (year) } \\
\hline 30-39 & 772 & $412(53.4)$ & 427 & $203(47.5)$ \\
\hline $40-49$ & 1214 & $735(60.5)$ & 879 & $461(52.4)$ \\
\hline $50-59$ & 1285 & $786(61.2)$ & 905 & $431(47.6)$ \\
\hline $60-69$ & 755 & $471(62.4)$ & 565 & $247(43.7)$ \\
\hline \multicolumn{5}{|c|}{ BMI at baseline $\left(\mathrm{kg} / \mathrm{m}^{2}\right)$} \\
\hline$\leq 24.9$ & 1615 & 903 (55.9) & 854 & $407(47.7)$ \\
\hline $25-29.9$ & 1630 & $976(59.9)$ & 1495 & 709 (47.4) \\
\hline $30-34.9$ & 569 & $379(66.6)$ & 370 & $192(51.9)$ \\
\hline$\geq 35$ & 205 & $139(67.8)$ & 54 & $32(59.3)$ \\
\hline \multicolumn{5}{|l|}{ Diabetes } \\
\hline Absent & 3958 & 2359 (59.6) & 2726 & $1316(48.3)$ \\
\hline Present & 68 & $45(66.2)$ & 50 & $26(52.0)$ \\
\hline
\end{tabular}

BMI, body mass index; HUNT, Nord-Trøndelag Health Study; LBP, low back pain.

to any major extent on age (table 1 ). The percentage of LBP at end of follow-up was greater in men with diabetes than in those without (table 1), but no such tendency was present among women.

In the corresponding analysis with complete adjustment, a statistically significant association was found among men between baseline diabetes and risk of chronic LBP in HUNT3 (table 2). Men with diabetes experienced $43 \%$ increased risk of chronic LBP at end of the 11-year follow-up. No association between diabetes and risk of chronic LBP was indicated in women (table 2), but the sex difference in associations was not statistically significant $(\mathrm{p}=0.17)$.

In the study of recurrence/persistence of chronic LBP, among persons with chronic LBP at baseline, a total of 2404 women (59.7\%) and 1342 men (48.3\%) experienced chronic LBP at follow-up (table 3 ). The percentage of individuals with chronic LBP in HUNT3 was somewhat larger among those reporting diabetes at baseline, in particular among women. However, in the analyses adjusted for other risk factors, no excess probability of LBP could be established among individuals with diabetes and chronic LBP at baseline (table 4).

No significant interaction between diabetes and any of the covariates was found. Analyses carried out with adjustment for age and BMI as continuous variables revealed no particular change in the risk estimates associated with diabetes. Additional adjustment for HADS score hardly changed the associations between diabetes and risk or recurrence/persistence of LBP in analyses including the individuals with known HADS scores. Thus, adding
Table 4 Associations between diabetes at baseline and recurrence/persistence of chronic LBP in HUNT3, among individuals with chronic LBP at baseline

\begin{tabular}{|c|c|c|}
\hline & Women & Men \\
\hline \multicolumn{3}{|c|}{ Adjustment for age } \\
\hline $\mathrm{RR}(95 \% \mathrm{Cl})$ & 1.09 (0.92 to 1.29$)$ & $1.13(0.86$ to 1.48$)$ \\
\hline$P$ value & 0.37 & 0.41 \\
\hline $\begin{array}{l}\text { Number of } \\
\text { individuals } \\
\text { included }\end{array}$ & 4026 & 2776 \\
\hline \multicolumn{3}{|c|}{ Adjustment for age and BMI } \\
\hline $\mathrm{RR}(95 \% \mathrm{Cl})$ & $1.06(0.90$ to 1.26$)$ & $1.08(0.82$ to 1.42$)$ \\
\hline$P$ value & 0.51 & 0.59 \\
\hline $\begin{array}{l}\text { Number of } \\
\text { individuals } \\
\text { included }\end{array}$ & 4019 & 2773 \\
\hline \multicolumn{3}{|c|}{ Complete adjustment* } \\
\hline $\mathrm{RR}(95 \% \mathrm{Cl})$ & 1.05 (0.87 to 1.27$)$ & $1.09(0.83$ to 1.43$)$ \\
\hline$P$ value & 0.61 & 0.54 \\
\hline $\begin{array}{l}\text { Number of } \\
\text { individuals } \\
\text { included }\end{array}$ & 3703 & 2633 \\
\hline
\end{tabular}

*Adjustment for baseline age, BMI, physical activity and smoking.

BMI, body mass index; HUNT, Nord-Trøndelag Health Study; LBP, low back pain; $R R$, relative risk.

adjustment for HADS to the complete model of risk of LBP considered for men produced a relative risk of 1.61 (95\% CI 1.17 to 2.23 ) among the 7826 individuals with information available, compared with a relative risk of 1.58 (95\% CI 1.14 to 2.19) without adjustment for HADS among exactly the same set of individuals.

\section{DISCUSSION}

In this cohort, an increased risk of chronic LBP was found in men with diabetes. In women, no association was observed between diabetes and risk of chronic LBP. Among persons with chronic LBP at start of follow-up, no association between diabetes and recurrence or persistence of chronic LBP after 11 years could be established in either sex.

A major strength of our study is the use of a large population-based data set collected in an entire county, with the great majority of the individuals belonging to a uniform ethnic group. ${ }^{23}$ Socioeconomic differences in this population are small. The area studied is representative of Norway, but does not include any major city. The total follow-up period of 11 years was substantially longer than in comparable cohort studies. ${ }^{319}$

Our study has several limitations. Diabetes diagnoses were based on self-reports in a questionnaire, but a validity study ${ }^{25}$ indicated that the information supplied by the participants on such diagnoses was largely consistent with medical record data. In general, however, a large 
proportion of those with diabetes have not received a formal diagnosis. ${ }^{32}$ If the failure to detect diabetes cases occurs at random, a true positive association with LBP will only be slightly attenuated. If, on the other hand, those without a formal diagnosis tend to have a lower risk of LBP, a positive bias may be created. Characteristics such as diabetes type or duration and use of medication were not taken into account in our analysis. An earlier study using cross-sectional HUNT data considering diabetes and migraine ${ }^{33}$ reported that the great majority of the diagnoses were likely of type 2 diabetes. Classical type 1 diabetes constituted about $6 \%$ and latent autoimmune diabetes of adults about $5 \%$ of all cases of diabetes. The diagnosis of chronic LBP in our study was also based on self-reports and only referred to the last year before each questionnaire was returned. Unfortunately no information was available about LBP in the remainder of the intervening period, complicating the exact definitions of recurrence or persistence. Moreover, with additional information on pain intensity, a more precise definition of chronic LBP could have been established. ${ }^{34}$ In any case, our results only apply to the age interval of 30-69 years at baseline, and no statements can be made in connection with diabetes diagnosed from the age of 70 years.

Although response rates in HUNT2 were relatively high, response rates were lower in the subsequent HUNT3 study, and minor parts of the cohort were lost because of death or movement out of the county. This will not affect the magnitude of relative risk estimates if loss to follow-up or participation rates at end of follow-up only depend on baseline diabetes status. However, such loss may be important if participation rates are associated with LBP to a different extent within categories of baseline diabetes status. Chronic LBP is a serious condition but is far from life threatening, so a major influence of this kind seems less likely. In particular, it is not to be expected that a bias of this kind should generate a false-positive association between diabetes and LBP within the age range considered. Individuals with a diabetes diagnosis may be more frequently in contact with the healthcare system, but LBP is not normally a medical condition that is detected unexpectedly on such occasions.

The statistical analysis of our data set was made more complicated by the fact that the category with diabetes at baseline constituted a relatively small fraction of the entire population at risk. Thus, the number of individuals in this category with LBP at follow-up was low, which made detailed analyses with more extensive adjustment for other potential risk factors difficult. Previous studies using HUNT data have found that BMI is strongly associated to both $\mathrm{LBP}^{10}$ and diabetes, ${ }^{35}$ and thus BMI is an important potential confounder. However, adjustment specifically for BMI led to only minor changes in risk estimates. BMI was grouped into four categories representing normal weight or underweight, overweight, obesity and severe obesity. Separate analyses with BMI regarded as a continuous variable did not indicate that residual confounding represented any major problem. Several other potential confounders of an association between diabetes and LBP showed only moderate variation between individuals in the particular population considered. Thus, socioeconomic status is largely uniform, and access to medical treatment is standardised in the public Norwegian healthcare system, including the entire population.

We were only able to adjust for HADS score in particular sensitivity analyses of a subset of the individuals considered. The estimated relationship between diabetes and risk of LBP among men was somewhat stronger in this subset, and it is possible that the individuals included were not entirely representative of the complete data set. Yet adjustment for HADS score did not weaken the relationship. It is still conceivable that confounding due to variables not adjusted for, in particular psychosocial factors incorporating other kinds of information, might affect relative risk estimates.

Among the few similar studies, a higher risk of back, neck and/or shoulder pain was found among men with diabetes in a large Swedish 4-year follow-up. ${ }^{19}$ A 2-4 years' follow-up of Spanish twins did not provide evidence that type 2 diabetes increases the risk of back pain, although higher OR estimates were found in men when diabetes was investigated as a risk factor for severe chronic LBP. ${ }^{3}$ A cross-sectional study in the USA using data from the National Health and Nutrition Examination Survey found higher prevalence of chronic LBP among participants with diabetes. ${ }^{18}$ Other kinds of studies have found mixed results concerning possible associations between diabetes and back pain. In data from the TwinsUK cohort, an association between type 2 diabetes and lumbar intervertebral disc degeneration disappeared after adjustment for BMI. ${ }^{36}$ In a Finnish cross-sectional study an association was found between chronic widespread pain including back pain and both diabetes and pre-diabetes. ${ }^{37}$ The prevalence of musculoskeletal pain including LBP was significantly higher in a Danish study of patients with type 2 diabetes matched against the general population. ${ }^{38}$ In a Norwegian follow-up study, increased risk of hip fractures was found among women with diabetes. ${ }^{39}$

An increased risk of chronic LBP in men with diabetes, as observed in our study, could be caused by shared risk factors between diabetes and LBP. However, considering the adjustment introduced here for BMI, physical activity and smoking, this seems less likely. It is also possible that diabetes has led to increased BMI and less physical activity during follow-up, and in this way an increased risk of chronic LBP. LBP has been associated with dyslipidaemia, ${ }^{40}{ }^{41}$ with atherosclerosis in the feeding arteries producing impaired blood flow to the lower back and possibly lumbar disc degeneration. ${ }^{42}$ Dyslipidaemia is related to insulin resistance and type 2 diabetes. ${ }^{43}$ Inflammation may also be related to both $\mathrm{LBP}^{44}$ and diabetes. ${ }^{45}$ The possibility that other kinds of comorbidity may affect the association between diabetes and LBP cannot be excluded, but it is not obvious whether the medical conditions involved would be part of a causal pathway from diabetes to LBP or not. 
In our data set, those who had chronic LBP at baseline in HUNT2 also had a much higher probability of chronic LBP at end of follow-up in HUNT3, but this probability did not depend on diabetes status at baseline. Few studies have explicitly addressed associations between risk factors and recurrence or persistence of LBP. ${ }^{10}{ }^{46-48}$ In a recent study among the HUNT population, women but not men who experienced chronic LBP were found to have an increased risk of being diagnosed with diabetes after 11 years. ${ }^{17}$ The sex difference reported in that study is not necessarily inconsistent with the present results, because the risk factor and the disease examined are exchanged. A difference in risk estimates between women and men was also found in the longitudinal analysis of LBP as a risk factor for type 2 diabetes in the Spanish twin study. ${ }^{3}$ It is known that there are general gender differences in noticing pain, ${ }^{49} 50$ which may affect the prevalence of LBP. Different levels of sex hormones may also lead to gender differences in associations with risk factors. ${ }^{29}$

Diabetes is known to be associated with a number of complications and a higher risk of other diseases as polyneuropathy, kidney and cardiovascular diseases. The results of this study indicate that chronic LBP might be considered another candidate for this list of associated disorders in men.

\section{CONCLUSIONS}

Men with diabetes may have a higher risk of chronic LBP. In women, no association has been established. These results need to be confirmed in studies from other populations.

\section{Author affiliations}

'Division of Clinical Neuroscience, Department of Research, Innovation and Education, Oslo University Hospital, Oslo, Norway

${ }^{2}$ Department of Mathematics, University of Bergen, Bergen, Norway

${ }^{3}$ Department of Neuromedicine and Movement Science, Norwegian University of Science and Technology, Trondheim, Norway

${ }^{4}$ Norwegian Advisory Unit on Headaches, St Olavs University Hospital, Trondheim, Norway

${ }^{5}$ Department of Public Health and Nursing, Faculty of Medicine and Health Sciences, HUNT Research Centre, Norwegian University of Science and Technology (NTNU), Trondheim, Norway

${ }^{6}$ Department of Endocrinology, St Olavs University Hospital, Trondheim, Norway

${ }^{7}$ Faculty of Medicine, University of Oslo, Oslo, Norway

Acknowledgements The Nord-Trøndelag Health Study (the HUNT Study) is a collaboration between HUNT Research Centre (Faculty of Medicine and Health Sciences, Norwegian University of Science and Technology (NTNU)), Nord-Trøndelag County Council, Central Norway Regional Health Authority, and the Norwegian Institute of Public Health.

Contributors InH, IvH, KH, EPS, BOÅ and JAZ contributed to the study design. InH and IvH contributed to analysis and interpretation of data. InH wrote the paper. IvH, $\mathrm{KH}, \mathrm{EPS}, \mathrm{BOÅ}$ and JAZ all revised the manuscript. All authors discussed the results, commented on the manuscript and approved the paper.

Funding The authors have not declared a specific grant for this research from any funding agency in the public, commercial or not-for-profit sectors.

Competing interests None declared.

Patient consent for publication Not required.
Ethics approval The work was approved by the Regional Committee for Medical and Health Research Ethics in Central Norway, and HUNT was also approved by the Norwegian Data Inspectorate.

Provenance and peer review Not commissioned; externally peer reviewed.

Data availability statement Data may be obtained from a third party and are not publicly available.

Open access This is an open access article distributed in accordance with the Creative Commons Attribution Non Commercial (CC BY-NC 4.0) license, which permits others to distribute, remix, adapt, build upon this work non-commercially, and license their derivative works on different terms, provided the original work is properly cited, appropriate credit is given, any changes made indicated, and the use is non-commercial. See: http://creativecommons.org/licenses/by-nc/4.0/.

\section{REFERENCES}

1. Maher $C$, Underwood M, Buchbinder R. Non-specific low back pain. The Lancet 2017;389:736-47.

2. Chatterjee S, Khunti K, Davies MJ. Type 2 diabetes. The Lancet 2017;389:2239-51.

3. Dario A, Ferreira M, Refshauge K, et al. Mapping the association between back pain and type 2 diabetes: a cross-sectional and longitudinal study of adult Spanish twins. PLoS One 2017;12:e0174757.

4. Jimenez-Garcia R, Del Barrio JL, Hernandez-Barrera V, et al. Is there an association between diabetes and neck pain and lower back pain? Results of a population-based study. J Pain Res 2018;11:1005-15.

5. Wilkens P, Scheel IB, Grundnes O, et al. Prognostic factors of prolonged disability in patients with chronic low back pain and lumbar degeneration in primary care: a cohort study. Spine 2013;38:65-74.

6. Real A, Ukogu C, Krishnamoorthy D, et al. Elevated glycohemoglobin $\mathrm{HbA1c}$ is associated with low back pain in nonoverweight diabetics. Spine J 2019;19:225-31.

7. Anekstein $\mathrm{Y}$, Smorgick $\mathrm{Y}$, Lotan $\mathrm{R}$, et al. Diabetes mellitus as a risk factor for the development of lumbar spinal stenosis. Isr Med Assoc $J$ 2010;12:16-20.

8. Fields AJ, Berg-Johansen B, Metz LN, et al. Alterations in intervertebral disc composition, matrix homeostasis and biomechanical behavior in the UCD-T2DM rat model of type 2 diabetes. J Orthop Res 2015;33:738-46.

9. Illien-Jünger S, Lu Y, Qureshi SA, et al. Chronic ingestion of advanced glycation end products induces degenerative spinal changes and hypertrophy in aging pre-diabetic mice. PLoS One 2015;10:e0116625.

10. Heuch I, Heuch I, Hagen K, et al. Body mass index as a risk factor for developing chronic low back pain: a follow-up in the Nord-Trøndelag Health Study. Spine 2013;38:133-9.

11. Kasim NB, Huri HZ, Vethakkan SR, et al. Genetic polymorphisms associated with overweight and obesity in uncontrolled type 2 diabetes mellitus. Biomark Med 2016;10:403-15.

12. Heuch I, Heuch I, Hagen K, et al. Is there a U-shaped relationship between physical activity in leisure time and risk of chronic low back pain? A follow-up in the HUNT Study. BMC Public Health 2016;16:306.

13. Mutie PM, Giordano GN, Franks PW. Lifestyle precision medicine: the next generation in type 2 diabetes prevention? BMC Med 2017; $15: 171$

14. Leboeuf-Yde C. Smoking and low back pain. A systematic literature review of 41 journal articles reporting 47 epidemiologic studies. Spine 1999;24:1463-70.

15. Maddatu J, Anderson-Baucum E, Evans-Molina C. Smoking and the risk of type 2 diabetes. Transl Res 2017;184:101-7.

16. Pozzobon D, Ferreira PH, Dario AB, et al. Is there an association between diabetes and neck and back pain? A systematic review with meta-analyses. PLoS One 2019;14:e0212030.

17. Heuch I, Heuch I, Hagen K, et al. Is chronic low back pain a risk factor for diabetes? The Nord-Trøndelag Health Study. BMJ Open Diabetes Res Care 2018;6:e000569.

18. Hassoon A, Bydon M, Kerezoudis P, et al. Chronic low-back pain in adult with diabetes: NHANES 2009-2010. J Diabetes Complications 2017;31:38-42

19. Pico-Espinosa OJ, Skillgate E, Tettamanti G, et al. Diabetes mellitus and hyperlipidaemia as risk factors for frequent pain in the back, neck and/or shoulders/arms among adults in Stockholm 2006 to 2010 - Results from the Stockholm Public Health Cohort. Scand J Pain 2017;15:1-7. 
20. Rinaldo L, McCutcheon BA, Gilder H, et al. Diabetes and back pain: markers of diabetes disease progression are associated with chronic back pain. Clin Diabetes 2017;35:126-31.

21. Heuch I, Heuch I, Hagen K, et al. A comparison of anthropometric measures for assessing the association between body size and risk of chronic low back pain: the HUNT Study. PLOS One 2015;10:e0141268.

22. Krokstad S, Langhammer A, Hveem K, et al. Cohort profile: the HUNT Study, Norway. Int J Epidemiol 2013;42:968-77.

23. Holmen J, Midthjell K, Krüger $\varnothing$, et al. The Nord-Trøndelag health study 1995-97 (Hunt 2): objectives, contents, methods and participation. Norw J Epidemiol 2003;13:19-32.

24. Bogduk N. Management of chronic low back pain. Med J Aust 2004;180:79-83.

25. Midthjell $\mathrm{K}$, Holmen J, Bjørndal A, et al. Is questionnaire information valid in the study of a chronic disease such as diabetes? The Nord-Trøndelag Diabetes Study. J Epidemiol Community Health 1992;46:537-42.

26. Zigmond AS, Snaith RP. The hospital anxiety and depression scale. Acta Psychiatr Scand 1983;67:361-70.

27. Langhammer A, Krokstad S, Romundstad P, et al. The HUNT Study: participation is associated with survival and depends on socioeconomic status, diseases and symptoms. BMC Med Res Methodol 2012;12:143.

28. Kurtze N, Rangul V, Hustvedt B-E, et al. Reliability and validity of selfreported physical activity in the Nord-Trøndelag Health Study (HUNT 2). Eur J Epidemiol 2007;22:379-87.

29. Kautzky-Willer A, Harreiter J, Pacini G. Sex and gender differences in risk, pathophysiology and complications of type 2 diabetes mellitus. Endocr Rev 2016;37:278-316.

30. Meucci RD, Fassa AG, Faria NMX. Prevalence of chronic low back pain: systematic review. Rev Saúde Pública 2015;49:73.

31. Shiri R, Karppinen J, Leino-Arjas P, et al. The association between obesity and low back pain: a meta-analysis. Am J Epidemiol 2010;171:135-54.

32. Khunti K, Mani H, Achana F, et al. Systematic review and metaanalysis of response rates and diagnostic yield of screening for type 2 diabetes and those at high risk of diabetes. PLoS One 2015;10:e0135702.

33. Hagen $\mathrm{K}$, Åsvold BO, Midthjell K, et al. Inverse relationship between type 1 diabetes mellitus and migraine. Data from the NordTrøndelag Health Surveys 1995-1997 and 2006-2008. Cephalalgia 2018;38:417-26.

34. Von Korff M, Dunn KM. Chronic pain reconsidered. Pain 2008:138:267-76.
35. Carlsson S, Midthjell K, Tesfamarian MY, et al. Age, overweight and physical inactivity increase the risk of latent autoimmune diabetes in adults: results from the Nord-Trøndelag Health Study. Diabetologia 2007;50:55-8.

36. Fabiane SM, Ward KJ, latridis JC, et al. Does type 2 diabetes mellitus promote intervertebral disc degeneration? Eur Spine $J$ 2016;25:2716-20.

37. Mäntyselkä P, Miettola J, Niskanen L, et al. Persistent pain at multiple sites--connection to glucose derangement. Diabetes Res Clin Pract 2009;84:e30-2.

38. Molsted S, Tribler J, Snorgaard O. Musculoskeletal pain in patients with type 2 diabetes. Diabetes Res Clin Pract 2012;96:135-40.

39. Forsén L, Meyer HE, Midthjell K, et al. Diabetes mellitus and the incidence of hip fracture: results from the Nord-Trøndelag Health Survey. Diabetologia 1999;42:920-5.

40. Heuch I, Heuch I, Hagen K, et al. Associations between serum lipid levels and chronic low back pain. Epidemiology 2010;21:837-41.

41. Heuch I, Heuch I, Hagen K, et al. Do abnormal serum lipid levels increase the risk of chronic low back pain? The Nord-Trøndelag Health Study. PLoS One 2014;9:e108227.

42. Kauppila L. Can low-back pain be due to lumbar-artery disease? The Lancet 1995;346:888-9.

43. Taskinen M-R, Borén J. New insights into the pathophysiology of dyslipidemia in type 2 diabetes. Atherosclerosis 2015;239:483-95.

44. Hashem LE, Roffey DM, Alfasi AM, et al. Exploration of the interrelationships between obesity, physical inactivity, inflammation, and low back pain. Spine 2018;43:1218-24.

45. Lontchi-Yimagou E, Sobngwi E, Matsha TE, et al. Diabetes mellitus and inflammation. Curr Diab Rep 2013;13:435-44.

46. van den Heuvel SG, Ariëns GAM, Boshuizen HC, et al. Prognostic factors related to recurrent low-back pain and sickness absence. Scand J Work Environ Health 2004;30:459-67.

47. Elders LAM, Burdorf A. Prevalence, incidence, and recurrence of low back pain in scaffolders during a 3-year follow-up study. Spine 2004;29:E101-E106.

48. van Oostrom SH, Verschuren WMM, de Vet HCW, et al. Ten year course of low back pain in an adult population-based cohort--the Doetinchem Cohort Study. Eur J Pain 2011;15:993-8.

49. Keogh E. Sex and gender differences in pain: a selective review of biological and psychosocial factors. The Journal of Men's Health \& Gender 2006;3:236-43.

50. Meints SM, Wang V, Edwards RR. Sex and race differences in pain sensitization among patients with chronic low back pain. $J$ Pain 2018;19:1461-70. 